\title{
À margem do abismo: uma interpretação poetológica de "Zürich, zum Storchen", de Paul Celan
}

\begin{abstract}
Juliana P. Perez*
Abstract: The poem "Zurich, zum Storchen" by Paul Celan is often read as a document on the tension between Celan and Nelly Sachs, which resulted particularly from their different attitudes to the Shoah. However if the poem is read in connection with the cycle Die Niemandsrose and with Celan's poetological thinking at this time, Celan's opposite standpoint means much more than a theological discussion: it serves for the affirmation of human presence.
\end{abstract}

Keywords: Paul Celan; Nelly Sachs; Poetry; Shoah.

Zusammenfassung: Das Gedicht "Zürich, zum Storchen" von Paul Celan wird oft als Zeugnis der Spannung zwischen ihm und Nelly Sachs gelesen, die vor allem durch die verschiedenen Einstellungen bezüglich der Schoah entstanden ist. Wird aber das Gedicht im Zusammenhang mit dem Zyklus Die Niemandsrose und mit der poetologischen Reflexion gelesen, die Celan zu dieser Zeit beschäftigte, dann geht Celans Gegenposition weit über eine theologische Diskussion hinaus: Sie gilt der Behauptung der menschlichen Präsenz.

Stichwörter: Paul Celan; Nelly Sachs; Lyrik; Schoah.

Palavas chave: Paul Celan; Nelly Sachs; Poesia; Shoá.

A autora é Professora de literatura alemã na Universidade Federal de Rio de Janeiro. 
1. „Entre Paris e Estocolmo..."

- „Zwischen Paris und Stockholm läuft der Meridian des Schmerzens und des Trostes", escreve Nelly Sachs a Paul Celan em outubro de 1959. (Celan/ SACHS 1993: 25). O meridiano da dor e do consolo, uma linha imaginária que une dois extremos - eis como poderia ser descrita a relação entre Celan e Sachs entre 1959 e 1961, período em que a amizade e a correspondência entre os dois poetas atingem seu ponto mais alto. Nos anos que se seguem, eles se distanciam, em parte por causa dos problemas pessoais que cada um enfrenta, em parte por causa de sua divergência em relação ao extermínio dos judeus durante a II. Guerra Mundial: Celan opõe-se veementemente a qualquer explicação religiosa para a Shoah, enquanto Nelly Sachs, mesmo hesitante, afirma sua fé.

Muitos críticos lêem o poema Zürich, zum Storchen, que Paul Celan escreve em maio de 1960, após um encontro com Nelly Sachs na Suíça, no hotel de mesmo nome, como um documento da tensão entre os dois poetas - leitura que encontra apoio nas anotações pessoais de Celan sobre o encontro, publicadas no volume de sua correspondência com Nelly Sachs (41). Zürich, zum Storchen seria, nessa perspectiva, mais um testemunho de uma Gegensprache, uma linguagem de negação e estranheza que Paul Celan teria buscado em toda sua obra (Cf. p. ex. Bollack 2003).

No entanto, quando se considera o poema no contexto do ciclo a que ele pertence - o livro Die Niemandsrose (BCA 6.1) - e da reflexão poetológica que ocupa Celan na época em que foi escrito, percebe-se que sua Gegensprache não é um fim em si mesma, mas serve a uma afirmação mais profunda: a afirmação do homem em sua efemeridade.

Para vislumbrar o aspecto afirmativo de um texto à primeira vista tão negativo, é preciso reconstruir alguns dados de seu processo de criação. Tal reconstrução diz respeito, por um lado, à gênese específica do poema, por outro, ao conjunto de dados como traduções, anotações, leituras, pensamentos, encontros e situações pessoais que determinam o uso da língua feito por Celan. Assim, trata-se de reconstruir o contexto de linguagem em que o poema surge e de observar seu movimento interno. 


\section{2. À margem do abismo: Gespräch im Gebirg e Die Niemandsrose}

Paul Celan escreve os poemas do livro Die Niemandsrose entre 1959 e 1963, ano em que foi publicado, e divide-os em quatro ciclos (BCA 6.2). Cada ciclo enfatiza um aspecto de sua reflexão poetológica: o primeiro se caracteriza pela oposição da poesia a um discurso que pode aniquilar o homem - o que Celan chama de "Gegenwort". O segundo enfatiza a questão da abertura como um ethos em relação à presença humana; como conseqüência dessa posição ética, o terceiro ciclo identifica amor à resistência; enquanto o quarto é uma decidida homenagem de Celan ao efêmero.

O poema Zürich, zum Storchen faz parte do primeiro ciclo e foi escrito quase um ano após os primeiros poemas do livro. Paul Celan escreve Es war Erde in ibnen, poema de abertura, em 27 de julho de 1959; Zürich zum Storchen surge em maio de 1960 e abre uma nova fase na gênese de Die Niemandsrose. ${ }^{1} \mathrm{O}$ intervalo na escritura do livro não significa de modo algum um tempo improdutivo. Nesse período, Celan dedica-se intensamente a diversos trabalhos: traduz vários autores, ${ }^{2}$ escreve Gespräch im Gebirg (GW) em agosto de 1959; em outubro, torna-se "Lektor" de Língua e Literatura Alemã na École Normale Supérieure. Em março de 1960, Celan redige o ensaio Die Dichtung Ossip Mandelstamms (TCA) e, algumas semanas depois,

1 De acordo com a datação dos poemas, Celan escreve com relativa regularidade de maio de 1960 a agosto de 1961, porém, o terceiro ciclo do livro só é terminado depois de uma pausa de seis meses. (BCA 6.1, 6.2).

2 „Die Überschneidung von eigener poetischer Arbeit und Übersetzung im Zeichen der Begegnung ist zu keinem Zeitpunkt ausgeprägter als während des Entstehung des Bandes Die Niemandsrose." (Gellhaus 1997: 394) De fato, no mesmo período, são publicados textos de vários autores traduzidos por Celan: BAZAINE, Jean. Notizen zurMalerei der Gegenwart (1959); CHAR, René. [übers. von Celan u.a.] Poésies. Dichtungen. (1959); Mandelstam, Ossip. Gedichte (1959); Valéry, Paul. Die junge Parze (1960); CARYOL, Jean. Im Bereich einer Nacht. Roman. (1961); JeSSENIN, Sergej. Gedichte. (1961); Drei russischer Dichter. (Sammlung) Alexander Block, Ossip Mandelstam, Sergej Jessenin (1963). Nove dos vinte e um sonetos de Shakespeare, que foram publicados no ano de 1967 pela editora Insel, foram traduzidos entre setembro de 1959 e fevereiro de 1961. (Fremde Nähe 1997: 87, 426). 
começa a redigir Der Meridian (TCA), discurso pelo recebimento do prêmio Büchner que condensa os pontos mais importantes de sua poetologia. Para Celan, a poesia possui uma função cognitiva, pois, por meio do poema, abre-se uma nova percepção - à qual corresponde um novo ethos - do tempo e da presença humana.

Todos esses trabalhos formam o pano de fundo dos poemas primeiro ciclo de Die Niemandsrose e confirmam a pertinência de uma interpretação que considere não somente esses poemas, mas todo o livro como uma longa reflexão sobre a poesia. Ela inicia no poema de abertura, Es war Erde in ihnen, e forma uma trama entre os poemas de cada ciclo e outros textos de Celan.

Embora não seja possível interpretar aqui o poema de abertura nem abordar os outros ciclos do livro, é importante ao menos mencionar algumas relações entre Es war Erde in ihnen, Gespräch im Gebirg e Zürich, zum Storchen, para compreender de que forma a reflexão poetológica acontece neste último.

O primeiro indício de que Es war Erde in ihnen apresenta uma tomada de posição a respeito do significado da poesia é literário: trata-se do diálogo com a poesia do poeta russo Ossip Mandelstam, a quem Die Niemandsrose é dedicado, e, especificamente, com seu ensaio Das Wort und die Kultur. (Mandelstam 1994). O segundo poderia ser chamado de factual: trata-se do famoso desencontro entre Celan e Adorno, em 22 de julho de 1959, cinco dias antes da criação do poema. A narração Gespräch im Gebirg (GW), que faz referência a Adorno e também é considerada um documento da poetologia de Celan, foi escrita mais tarde, em agosto de 1959 - porém a decisão poetológica de não falar a partir de uma perspectiva panorâmica já havia sido tomada. ${ }^{3}$ A relevância de Gespräch im Gebirg e do embate com

3 Há muito tempo a crítica conhece uma anotação de Celan, encontrada no espólio do ciclo Atemwende, a respeito da frase de Adorno sobre a barbárie da poesia após Auschwitz: "Kein Gedicht nach Auschwitz (Adorno): was wird hier als Vorstellung von "Gedicht" unterstellt? Der Dünkel dessen, der sich untersteht hypothetisch - spekulativerweise Auschwitz aus der Nachtigallenoder Singdrossel-Perspektive zu betrachten oder zu berichten" (Apud: GellHaus 1995: 304). 
Adorno para a poetologia de Celan também é enfatizada em Der Meridian, através da figura de Lenz. ${ }^{4}$

Gespräch im Gebirg serve como ponte entre o livro Sprachgitter (BCA 5.1/5.2) terminado há pouco tempo, e Die Niemandsrose, apenas iniciado, na medida em que a reflexão poetológica de Celan torna-se sempre mais clara. ${ }^{5}$ Chama a atenção a imagem da poesia como caminhar, que já era anunciada no poema Engfübrung, de Sprachgitter, e no discurso de Bremen (GW). O caminhar da poesia - sempre caracterizado como escuro - possui uma relação estreita com outros aspectos da reflexão poetológica de Celan: com a imagem do abismo, com o questionamento sobre o eu e sobre o tempo.

O primeiro parágrafo de Gespräch im Gebirg (169) apresenta a imagem do judeu que "ia" e "vinha" no escuro. A escuridão marcará, sobretudo, os poemas do primeiro ciclo de Niemandsrose; não por acaso, Celan reuniu, nessa mesma época, uma pasta de anotações com o título Von der Dunkelheit des Dichterischen, que mais tarde deveriam se tornar um ensaio (TCA 1999: X). Em novembro de 1959, ele reforça, em carta a Johannes Brobowski, a necessidade de andar no „lado noturno“ do mundo:

4 Joachim Seng chega a comparar a relação entre Celan e Adorno à relação entre Celan e Heidegger. Seng também lembra que esta relação não se restringe ao comentário de Adorno sobre a poesia após Auschwitz. A correspondência entre Adorno e Celan, publicada nos últimos anos, confirma que Celan leu intensamente os escritos de Adorno. Seng relaciona vários trechos de Der Meridian a pensamentos de Adorno, sobretudo no que diz respeito à Selbstvergessenheit do eu através da arte. (Cf. SENG 1998: 260-268; SENG 2003: 151-202).

5 Sobre a narração, Axel Gellhaus afirma: "Der Dissoziierung des Ich und der Wahrnehmung folgt die Sprachkritik. [...] Es ist merkwürdig, daß in diesem gekonnt unartifiziellen Sprachduktus der Erzählung zweimal auf Lenz verwiesen wird, also auf Büchner und damit wohl auf ein literarisches Programm. Es ist das Programm, das Celan in der Büchner-Preis-Rede ausführen wird, ein antiklassizistisches, antiidealistisches und antiästhetizistisches; positiv formuliert, ein Programm der 'radikalen Individuation'.” (GellHaus 2004: 210). Uma análise mais antiga do texto foi feita por Dorothea Kohler-Luginbühl. Muitas observações da autora foram corrigidas e aprofundadas pela pesquisa mais atual, mas o texto tem o mérito de ser um dos poucos a interpretar Gespräch im Gebirg, de forma detalhada, do ponto de vista poetológico. 
Was kann man in dieser Welt und dieser Zeit einem Brief (oder einem Gedicht) denn mitgeben als eben dies: ein Unausgesprochenes, eben noch "Stimmhaftes", das, ach, so selbstverständlich ist? (...) Es gibt nur diese eine Welt, sie hat - auch hier, wo ich lebe - ihre Nachtseite, wir brauchen nicht erst hinzufliegen, und sie zu photographieren... Nur die Hände haben es so weit zueinander. (apud Bobrowski 1996: 425)

A decisão de andar e não de voar - que também está presente em Das Wort vom Zur-Tiefe-Gehn, segundo poema do livro -, aliás, de caminhar no escuro, é sempre retomada. A escuridão também está relacionada ao andar de ponta-cabeça ("auf-dem-Kopf-Gehen”) de Lenz e, portanto, à imagem do abismo e do tempo, como documentam inúmeras anotações de Celan de agosto de 1959:

Von der Erfahrung verspreche ich mir, ohne allzu zahlreiche Begriffsentlehnungen auszukommen. Ferner versuche ich, im Hinblick auf die Heutigkeit des Gedichts, hier und im folgenden auf jede Ätiologie zu verzichten. Ich habe das Gedicht vor mir.

Vorstellung und Erfahrung, Erfahrung und Vorstellung lassen mich, in Ansehnung der Dunkelheit des Gedichts heute, an eine Dunkelheit des Gedichts als Gedicht denken, an eine konstitutive, kongenitale Dunkelheit also. Mit andern Worten: das Gedicht kommt dunkel zur Welt; es kommt, als Ereignis radikaler Individuation, als ein Stück Sprache zur Welt, somit, d.h., sofern Sprache Welt zu sein vermag, mit Welt befrachtet.” (Nota de 17. 08. 59. TCA 1999: 84, N. 102)

A escuridão caracteriza a presença, a proximidade - pois Celan fala da "hodiernidade do poema" ("Heutigkeit des Gedichts") e da "escuridão do poema hoje" ("Dunkelheit des Gedichts heute"). A partir do hoje, é possível pensar em uma "escuridão constitutiva, congênita, do poema" ("konstitutive, kongenitale Dunkelheit des Gedichts”). O poema é escuro graças à "individuação radical" ("radikale Individuation"), isto é, graças às experiências concretas de um eu que o poema traz consigo. Recorde-se aqui a percepção tensa do próprio eu como um fato inevitável em Gespräch: 
Hörst du, sagt er, ich bin da. Ich bin da, ich bin hier, ich bin gekommen. Gekommen mit dem Stock, ich und kein anderer, ich und nicht er, ich mit meiner Stunde, der unverdienten, ich, den's getroffen hat, ich, den's nicht getroffen hat, ich mit dem Gedächtnis, ich, der Gedächtnisschwache, ich, ich, ich... (GW: 171)

Para Celan, no poema, a escuridão caracteriza a presença e, conseqüentemente, a percepção do eu em um tempo concreto de sua existência. O próximo passo é a pergunta pelo "Grund", pelo "chão", o "fundo", o "motivo", sobre o qual o eu poderia se apoiar.

Das Gedicht hat, wie der Mensch, keinen zureichenden Grund. Daher seine spezifische Dunkelheit, die in Kauf genommen werden muß, wenn das Gedicht als Gedicht verstanden sein soll. Vielleicht auch: das Gedicht hat seinen Grund in sich selbst; mit diesem Grund ruht es im Grundlosen. (19.8.59, TCA 1999: 88, N. 123)

Com a recusa de um "zureichender Grund", Celan recusa a linguagem de certa tradição filosófica que pretende dar uma explicação exaustiva e racionalista para a existência. ${ }^{6}$ A "Grundlosigkeit", ausência de fundamento ou razão ou motivo, da qual se fala aqui, consiste na percepção de um "mistério" ("Geheimnis") da poesia, como Celan formulará mais tarde: o poema não tem nenhuma razão suficiente, ou seja, nada que o possa esclarecer de forma analítica, exaustiva e causal. Ao afirmar que "o poema tem sua razão em si mesmo" ("das Gedicht hat seinen Grund in sich selbst"), Celan não confessa o princípio da arte pela arte, mas afirma que o poema carrega consigo seu motivo, não pode ser separado dele. Em outra anotação, a razão do poema - portanto, o porquê da escrita - é compreendida, paradoxalmente, como pergunta: o abismo parece estar sempre aberto.

Talvez fosse possível enxergar aqui uma alusão crítica ao texto Vom Wesen des Grundes, de Heidegger. A pesquisa de Robert Andrés sobre a relação entre os dois autores não cita essa possibilidade, porém, Celan anotou este título de Heidegger em uma mesma nota sobre Sein und Zeit. (Cf. TCA 1999: 210, N. 937.) 
Das Gedicht hat Gründe - und diese Gründe verbirgt es uns nicht; das Gedicht und des Gedichts Gründe aber haben keinen zureichenden Grund, es sei denn diesen: die Frage nach ihm. (19. 8. 59, TCA 1999: 88, N. 125)

No mesmo dia, Celan reflete sobre a relação entre "Dunkelheit" e "Gegenwart"- o que está no passado parece ser menos escuro:

Weshalb uns die Gedichte früherer Epochen "verständlicher" vorkommen als die unserer Zeitgenossen? Vielleicht auch deshalb, weil sie sich als Gedichte, d.h. mitsamt ihrem Dunkel schon verflüchtigt haben... (Nota de 19. 8. 59, TCA 1999: 85, N. 109)

Outras anotações da última semana de agosto documentam a reflexão de Celan sobre diversas questões poetológicas. No que diz respeito à escuridão, ele ainda escreve em 30 de agosto - provavelmente depois da redação de Gespräch im Gebirg:

Im Gedicht ereignet sich etwas, passiert etwas: die Sprache als Dasein passiert die Enge dessen, der das Gedicht schreibt; sie geht hindurch und vorbei. (TCA 1999: 115, N. 320)

Die Dunkelheit des Gedichts = die Dunkelheit des Todes. Die Menschen $=$ die Sterblichen. Darum zählt das Gedicht, als das des Todes eingedenk bleibende, zum Menschlichsten am Menschen. Das Menschliche ist aber nicht, das haben wir inzwischen ausgiebig erfahren, das Hauptmerkmal der Humanisten. Die Humanisten sind diejenigen, die über den konkreten Menschen hinweg in das Unverbindliche der Menschheit blicken. (TCA, 1999: 89, N. 130)

Quase um ano após sua redação, Gespräch im Gebirg é impresso e enviado por Celan a Adorno, em 23 de maio de 1960. (Cf. CELAn/Adorno 2003: 177-202) Os meses de abril de maio de 1960 são especialmente intensos para Celan: no início de abril, Claire Goll renova as acusações de plágio (Wiedemann 2000: 251s); no mesmo mês, Celan visita o poeta Jules Supervielle, que falece poucas semanas depois (Harbusch 2001: 117). Por causa da campanha pública contra si, Celan encontra-se em 10 de maio 
com Otto Pöggeler em Bonn; dois dias depois, ele viaja para Frankfurt, para se informar sobre seus direitos com Rudolf Hirsch e o advogado da editora Fischer (Wiedemann 2000: 501). De volta a Paris, Celan recebe a carta de Hermann Kasack, presidente da Deutsche Akademie für Sprache und Dichtung, datada de 11 de maio, com a notícia da outorga do prêmio Büchner. Em sua carta de agradecimento, escrita em 16 de maio, como também na carta a Hans Bender, de 18 de maio, Celan formula alguns dos pensamentos mais importantes de sua poetologia, que voltam a emergir com toda força em Der Meridian (TCA 1999: XII):

Diesen Preis, der den Namen Georg Büchners trägt, annehmen zu dürfen: mir bedeutet das, vor allem, Begegnung. Begegnung, Menschennähe, Begegnung mit einem hohen Namen der Seelenmonade Mensch. [...] Worte, zumal im Gedicht, - sind das nicht werdende und vergehende - Namen? Sind Gedichte nicht dies: die ihrer Endlichkeit eingedenk bleibende Unendlichsprechung von Sterblichkeit und Umsonst? (Entschuldigen Sie, bitte, die Emphase: sie gehört zu dem Staube, der uns und unsere stimmhaft-stimmlosen Seelen freisetzt und aufnimmt.) (TCA 1999: 222)

Na carta, Celan refere-se mais uma vez a Gespräch im Gebirg e ao caminho de Lenz. A percepção da finitude e sua constante lembrança no poema "Unendlichsprechung von Sterblichkeit und Umsonst" - são novamente relacionadas ao caminhar. Celan ainda acrescenta ao pensamento outro fator: o poema como "Handwerk" é descrito mais exatamente como o trabalho sem chão ("bodenlose Arbeit") de um homem que procura um caminho no escuro:

Dieses Handwerk hat ganz bestimmt keinen goldenen Boden - wer weiß, ob es überhaupt einen Boden hat. Es hat seine Abgründe und Tiefen - manchen (ach, ich gehöre nicht dazu) haben sogar einen Namen dafür.

Handwerk - das ist eine Sache der Hände. Und diese Hände wiederum gehören nur einem Menschen, d.h., einem einmaligen und sterblichen Seelenwesen, das mit seiner Stimme und seiner Stummheit einen Weg sucht. [...] Gewiß, es gibt Exerzitien - im geistigen Sinne, lieber Hans 
Bender! Und daneben gibt es eben, an jeder lyrischen Straßenecke, das Herumexperimentieren mit dem sogenannten Wortmaterial. Gedichte, das sind auch Geschenke - Geschenke an die Aufmerksamen. Schicksal mitführende Geschenke. [...] Wir leben unter finsteren Himmeln, und - es gibt wenig Menschen. Darum gibt es wohl auch so wenig Gedichte. Die Hoffnung, die ich noch habe, sind nicht groß; ich versuche, mir das mir Verbliebene zu erhalten. (CELAN 1983: 177-178)

A busca do indivíduo por um caminho - que pode ser vista em Celan como uma das condições da possibilidade da poesia - está em clara oposição ao generalizado "Herumexperimentieren" (experimentar por aî) com palavras, que na verdade não seguem um caminho, mas se deixam vender em qualquer esquina ("Straßenecke"). Celan designa o mau propósito de tais jogos de palavras como "Machenschaft" - em alusão à campanha de difamação. A ameaça sentida nesta atmosfera - "finstere Himmel" ("céus tenebrosos") - consiste na possível aniquilação da pessoa. O poema, porém, coloca-se contra ela como documento de uma "única e mortal alma" ("einmaligen und sterblichen Seelenwesen"), que só pode ser lida por aquele que está atento, der "Aufmerksame".

O pensamento da poesia como um caminho escuro possui diversas facetas: o sujeito do caminhar é sempre único - representado metonimicamente pelas mãos -; o tempo é o presente, traz a data do hoje; o hoje, porém, é passageiro, o indivíduo é caracterizado pela mortalidade. Invertem-se o modo e o espaço do caminhar: não se anda em um chão seguro, mas sobre um abismo. Como Lenz, o eu não consegue andar muito tempo de ponta cabeça ("Nur war es ihm manchmal unangenehm, daß er nicht auf dem Kopf gehen konnte'): ele precisa andar 'normalmente'. Nas diversas anotações de Celan, a escuridão toca todas esses aspectos: o indivíduo, a atualidade (Gegenwärtigkeit), a mortalidade e o abismo.

Assim, os poemas do livro Die Niemandsrose aprofundam as decisões poetológicas que Celan anunciara na obra anterior, Sprachgitter, em Gespräch im Gebirg, no ensaio sobre a poesia de Mandelstam e no discurso Der Meridian.

De abril, maio e junho datam inúmeras anotações, textos e rascunhos cujos temas serão abordados na Büchner-Rede e que, portanto, também determinam a gênese do poema "Zürich, zum Storchen": a oposição entre 
arte e poesia (Kunst vs. Dichtung), representada pela “Gegenwort” de Lucile, que por amor, mas sem ingenuidade, celebra o absurdo da presença humana; Lenz e o abismo; a questão da escuridão da poesia moderna; a poesia no mistério do encontro e, por fim, a própria imagem do meridiano.

Mas para compreender como a reflexão poetológica de Celan coincide com a reflexão existencial sobre as contradições das experiências daquele período e como tal reflexão está implicada em Zürich, zum Storchen, é preciso avançar mais um passo na questão da Dunkelheit.

\section{Abismo e escuridão: Lenz e Pascal}

A partir de meados dos anos cinqüenta, a crítica literária identificou a idéia da "escuridão" com o assim chamado "hermetismo", sobretudo, por causa do livro de Hugo Friedrich, Die Struktur der modernen Lyrik, , que deu impulso a muitas interpretações (errôneas) da obra de Celan. Em seus textos, a escuridão possui outro significado: ela não é um "princípio estético", que

„Moderne Lyrik nötigt die Sprache zu der paradoxen Aufgabe, einen Sinn gleichzeitig auszusagen wie zu verbergen. Dunkelheit ist zum durchgängigen ästhetischen Prinzip geworden. Sie ist es, die das Gedicht übermäßig absondert von der üblichen Mitteilungsfunktion der Sprache, um es in einer Schwebe zu halten, in der es sich eher entziehen als annähern kann. Manchmal scheint es, als ob modernes Dichten nur ein Notieren von Ahnungen und blinden Experimenten sei, aufbewahrt für irgendeine Zukunft, in der hellere Ahnungen und geglücktere Experimente sich an ihm entzünden könnten. [...] Die Dunkelheit liegt in den Gehalten wie in den stilistischen Mitteln. Das Gedicht spricht von Vorgängen, Wesen oder Dingen, über deren Ursache, Ort, Zeit der Leser nicht informiert ist und nicht informiert wird. [...] Dunkelheit kommt aus der Abschirmung gegen die äußere Welt; die innere öffnet sich; vom Lärm und Tödlichen des Lebens frei, macht sich das Dunkel - das Wegsein des Realen - zum Licht, wird zur Geburt der nur im Licht des Dunkeln erblühende Rose (,Rose` ist, wie bei Mallarmé, das Symbol des dichterischen Wortes, hier [bei Guillén] aber ohne das Thema des Mißlingens). Erst in der Irrealität, die das Dichten nötigt, dunkel zu sein, glückt die Vollendung des Dichtens. In diesem Gedanken liegt eine Grundentscheidung moderner Lyrik. Vor etwa zwanzig Jahre kam in Italien eine Bezeichnung für dunkles Dichten auf: Hermetismus.“ (FrIEDRICH 1956: 130-131). 
se apóia na "irrealidade" e que se alcança com meios estilísticos, mas pertence a uma categoria do conhecimento: "escuridão" caracteriza uma certa percepção da realidade, a percepção de um "mistério", que acontece de diversas formas - por meio do eu, do hoje, da morte e do caminho.

Também se encontra um sinal deste pensamento em um rascunho de 17 de maio de 1960 para o discurso do prêmio Büchner:

Zur 'Mitwisserschaft', aus der wir entlassen werden:

Mit jedem Gedicht stehen wir "gedichtlang", im Geheimnis. Von diesem Aufenthalt kommt das "Dunkel". (TCA 1999: 90, N. 135)

No mesmo dia, Celan anota mais algumas idéias fundamentais: a frase de Pascal: ("Pascal: Ne nous reprochez pas l'obscurité, puisque nous en faisons profession.", N. 136); duas observações sobre Hofmannsthal ("pointe acérée de l'infini"; "unter der Dienertreppe", N. 137-138) e, novamente, a definição de Lenz par excellence: "auf dem Kopf gehen". (N. 138)

O material publicado na edição crítica de Der Meridian mostra que Celan não anota as frases de Pascal do original, mas as cita a partir de outros textos, entre eles, um artigo de Leo Schestow. O texto - que será amplamente citado aqui devido à dificuldade do acesso a ele - inicia com uma crítica aguda à filosofia da história racionalista e com a oposição entre as figuras de Pascal e Descartes, como símbolos de duas formas de pensar opostas. ${ }^{8}$ Em seguida, ele apresenta a filosofia de Pascal como combate público

8 "Als Vater der neuen Philosophie gilt uns nicht Pascal, sondern Descartes. Und die Wahrheit empfangen wir nicht von Pascal, sondern von Descartes, denn wo anders sollte man die Wahrheit suchen, als bei der Philosophie? So ist nun einmal das Urteil der Geschichte: man bewundert Pascal und geht an ihm vorüber. [...] Was würde wohl Pascal auf das Urteil der Geschichte erwidern, wenn es möglich wäre, ihn zum Leben zu erwecken? Eine müßige Frage, wird man sagen. Die Geschichte rechnet nicht mit den Toten, sondern mit Lebenden. Gewiß. Immerhin will ich annehmen, daß es gut wäre, dies eine Mal, Pascal zuliebe, die Geschichte zu zwingen, auch mit den Toten zu rechnen. [...] In der Tat, die Geschichte würde in diesem Falle eine neue Philosophie sich ausdenken müssen, denn die Hegelsche Geschichtsphilosophie [...] würde sich dann als ungeeignet erweisen. Wäre es denn so schlimm, daß man sich einiger Mühe 
contra filósofos e teólogos que procuram "segurança" na razão cartesiana. ${ }^{9} \mathrm{Na}$ interpretação de Schestow, a tarefa dessa filosofia não é mais dormir, mas vigiar sem trégua, ${ }^{10}$ portanto, não se apoiar em um motivo mensurável pela "razão", mas andar à margem de um abismo. ${ }^{11} \mathrm{O}$ artigo continua pesquisando essas linhas mestras em detalhe (e também a posição de Pascal contra o estoicismo e o pelagianismo) e define o significado do eu na filosofia de Pascal. ${ }^{12}$ Pergunta-se pelo sentido da lei e da justiça, a razão racionalista é criticada mais uma vez, e neste contexto é citada a frase que Celan anota:

unterziehen müssen würde? Und ist es denn so sehr notwendig, Hegel um jeden Preis zu verteidigen? [...] Gegenwärtig glauben wir, gegenwärtig sind wir überzeugt, daß die Toten schweigen und ewig schweigen werden, was auch immer man von ihnen sprechen, wie auch immer man mit ihnen umgehen möge. Wenn uns aber diese Zuversicht genommen würde, wenn wir plötzlich das Gefühl bekämen, daß der Tote jeden Augenblick zum Leben erwachen, aus dem Grabe steigen, in unser Leben einbrechen und, ein Gleicher vor Gleichen, vor uns hintreten könnte - welche Sprache würden wir dann sprechen?" (SCHESTOw 1925: 38).

$9 \quad$ "Je ne puis pardonner à Descartes; il aurait bien voulu, dans toute sa philosophie, pouvoir se passer de Dieu; mais il n'a pas su s'empêcher de lui faire donner une chiquenaude, pour mettre le monde en mouvement; après cela, il n'a plus que faire de Dieu." Es ist ganz klar, daß die Worte: "Ich kann nicht verzeihen" sich nicht nur auf Descartes, sonder auch auf die ganze ihm vorausgegangene Philosophie beziehen, der Descartes seine Schulung verdankte, und auch auf die ganze Philosophie nach Descartes, die von ihm ihre Schulung empfing. [...] Pascal fühlte das bereits sehr früh, und seine ganzen letzten Lebensjahre waren ein ununterbrochener, qualvoller Kampf gegen die Welt und Rom, die danach trachteten, sich von Gott zu emanzipieren. Daher der rätselhafte paradoxe Charakter seiner Philosophie und seiner Lebensauffassung." (40 -41).

10 Para Leo Schestow, a idéia da vigília está resumida na frase de Pascal: "Jésus sera en agonie jusqu’à la fin du monde: il ne faut pas dormir pendant ce temps-là!”. (41).

11 "Nous brûlons de désir de trouver une assiette ferme et une dernière base constante, pour y édifier une tour qui s'élève à l'infini. Mais tout notre fondement craque et la terre s'ouvre jusqu'aux abîmes. Ne cherchons donc point d'assurance et de fermeté!" (Pascal, apud Schestow, 50).

12 "In der Tat, Pascal mag noch so viel davon sprechen, daß das Ich hassenswert sei, in Wirklichkeit aber richtet er alle seine Kräfte darauf, unser Ich gegen die Anmaßungen der immateriellen und ewigen Wahrheiten zu schützen.” (76). 
Wir erinnern uns, wie er [Pascal] sich von den einzigen und immateriellen, von der Renaissance verkündeten Wahrheiten gänzlich lossagte, wie sehr er Descartes haßte und das 'summum bonum' des antiken Philosophen verachtete... Es gibt nur einen Weg, um alledem zu entgehen: auf die 'veritates aeternae', auf die Früchte vom Baume der Erkenntnis verzichten - "s'abêtir". An nichts von alledem glauben, was die Vernunft verheißt. Die lichterfüllten Gegenden verlassen, denn das Licht macht die Lüge offenbar. Die Finsternis lieb gewinnen. "Qu'on ne nous reproche pas le manque de clarté, car nous en faisons profession." (89)

$\mathrm{O}$ artigo ainda esclarece a teoria do conhecimento de Pascal ${ }^{13}$ e trata da questão do sofrimento na figura de Jó. ${ }^{14} \mathrm{O}$ contexto da frase sobre "le manque de clarté", anotada por Celan em diversos momentos, mostra que, para ele, a escuridão faz jus a aspectos da realidade não percebidos pela razão racionalista. Pascal parece confirmar a Paul Celan a necessidade de abandonar todo conhecimento a priori e abstrato, para entrar na 'escuridão', em algo desconhe-

13 „Von der biblischen Offenbarung inspiriert, schafft Pascal eine ganz eigenartige "Erkenntnistheorie", die zu unseren Vorstellungen vom Wesen der Wahrheit im direkten Widerspruch steht. Die erste Grundvoraussetzung oder das erste Axiom der Erkenntnis lautet folgendermaßen: jeder normale Mensch kann die Wahrheit erkennen, wenn man sie ihm zeigt. Pascal, für den die Bibel die Hauptquelle der Erkenntnis ist, sagt folgendes: “On n'entend rien aux ouvrages de Dieu, si on ne prend pour principe qu'il a voulu ... aveugler les uns et éclairer les autres." (89).

14 O artigo de Schestow termina com o seguinte parágrafo: "Jésus sera en agonie jusqu'à la fin du monde”. Gott selbst hat zu den Leiden Hiobs seine eigenen endlosen Leiden hinzugefügt, und bis zum Ende der Welt wird der göttliche und menschliche Jammer schwerer wiegen als der Sand am Meere. Vorläufig aber - und darin liegt das Wesen der Philosophie Pascals, die mit dem, was sich gemeinhin Philosophie nennt, so wenig Ähnlichkeit hat - "ne cherchons pas assurance et fermeté" in unserer natürlichen verzauberten Welt. Man darf nicht ruhig sein, darf nicht schlafen. Nicht für jedermann gilt dies Verbot, sondern nur für einige wenige "Auserwählte" - oder "Märtyrer". Denn wenn auch diese in Schlaf fielen, wie der große Apostel in jener denkwürdiger Nacht, so wäre das Opfer Gottes vergeblich, und der Tod würde endgültig und für immer in der Welt triumphieren.“ (101). 
cido. O desconhecido também carrega algo de ameaçador, pois nada garante que o "porvir" ("das Kommende") esteja a favor do homem.

O conhecimento de algo novo tem uma condição: a abertura, que caracterizará principalmente os poemas do segundo ciclo do livro. Não por acaso unem-se aqui as reflexões de Celan sobre a "escuridão do poético" (Von der Dunkelheit des Dichterischen) e a redação, em março de 1960, do ensaio sobre a poesia de Mandelstam. Celan também aproveita dois longos parágrafos deste texto em Der Meridian. No primeiro, trata-se do eu; no segundo, do diálogo e dos "intervalos" ("Intervalle") em que o tempo do outro pode ser encontrado.

1. Sprecher: Diese Gedichte sind die Gedichte eines Wahrnehmenden und Aufmerksamen, dem Erscheinenden Zugewandten, das Erscheinende Befragenden und Ansprechenden; sie sind Gespräch. Im Raum dieses Gespräches konstituiert sich das Angesprochene, vergegenwärtigt es sich, versammelt es sich um das es ansprechende und nennende Ich. Aber in diese Gegenwart bringt das Angesprochene und durch Nennung gleichsam zum $D u$ Gewordene sein Andersund Fremdsein mit. Noch im Hier und Jetzt des Gedichts, noch in dieser Unmittelbarkeit und Nähe läßt es seine Ferne mitsprechen, bewahrt es das ihm Eigenste: seine Zeit.

2. Sprecher: Es ist dieses Spannungsverhältnis der Zeiten, der eigenen und der fremden, das dem mandelstamm'schen Gedicht jenes schmerzlich-stumme Vibrato verleiht, an dem wir es erkennen. (Dieses Vibrato ist überall: in den Intervallen zwischen den Worten und den Strophen, in den "Höfen", in denen die Reime und die Assonanzen stehen, in der Interpunktion. All das hat semantische Relevanz:) Die Dinge treten zueinander, aber noch in diesem Beisammensein spricht die Frage nach ihrem Woher und Wohin mit - eine "offenbleibende", "zu keinem Ende kommende", ins Offene und Besetzbare, ins Leere und Freie weisende Frage. (TCA 1999: 216; Cf. $9-10)$

O interesse de Celan pela poesia é "perceber" ("wahrnehmen"), "prestar atenção" ("aufmerken”), dirigir-se ao que "surge" ("erscheint”) e "interrogálo" ("befragen") - ações características de um ímpeto de conhecimento. 
D Nesse sentido, Celan objetiva a afirmação de uma realidade que não se esgoNa ta no já conhecido - que, por sua vez, precisa ser negado. O conhecimento - nunca é exaustivo: a pergunta permanece aberta, não tem fim, indica ao mesmo tempo o aberto, que será "ocupado" ("besetzt") por um novo

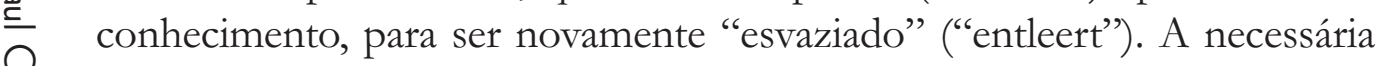
$\frac{\widehat{O}}{\frac{O}{\sigma}}$ abertura para tanto se torna atenção à presença do outro, que deve ser continuamente conhecido.

Algumas semanas após redigir o ensaio sobre Mandelstam, Celan formula o início e o final de seu discurso propriamente dito:

21.V.60

Liebe Freunde des Gedichts

Anfang:

"Nur es war ihm manchmal unangenehm..."

Wir schreiben noch immer, wir schreiben auch heute den 20. Jänner. Sehen wir uns um - wir sind (gehen durchs) im Gebirg - wir gehen durchs Gedicht - eines Tages, wenn wir nur das Geschriebene sind, werden wir, wie Lenz, aufgelesen auf der Straße - es muß keine Moskauer Straße sein.

Ende: Ich danke Ihnen für Ihre Aufmerksamkeit in beiderlei Gestalt Aufmerksamkeit, d.i. - ich zitiere ein Wort von Malebranche, ich zitiere es nach dem erstmalig in der Jüdischen Rundschau vom... veröff. Kafka-Essay Walter Benjamins - "Aufm.t d.i. die natürl. Frömm.t der Seele - (TCA 1999: 68, N. 51)

Esse primeiro rascunho de Der Meridian resume a reflexão poetológica de Celan entre 1959 e 1960: ele inicia com Lenz, com o caminhar, a escuridão e o abismo; passa, com Pascal, a uma crítica aguda ao modo de pensar racionalista, para afirmar a 'atenção', a abertura, como o comportamento humano par excellence diante de um outro e de uma realidade a serem conhecidos.

\section{Zürich, zum Storchen}

Quando Paul Celan escreve, em 30 de maio, o poema Zürich, zum Storchen para Nelly Sachs (BCA 6.1: 16) e, assim, retoma a redação de Die Niemandsrose, ele não tem apenas o encontro com a poetisa em mente, mas todas as 
experiências contraditórias daqueles meses e as conseqüentes decisões poetológicas. ${ }^{15} \mathrm{O}$ denso contexto que serve como pano de fundo deste poema dá aos dados reais do encontro um significado que vai além do "Erlebnis" descrito, na medida em que eles podem ser lidos como indicações poetológicas. ${ }^{16}$

\author{
Zürich, zum Storchen \\ Für Nelly Sachs \\ Vom Zuviel war die Rede, vom \\ Zuwenig. Von Du \\ und Aber-Du, von \\ der Trübung durch Helles, von \\ Jüdischem, von \\ deinem Gott. \\ $\mathrm{Da}-$ \\ von.
}

Am Tag einer Himmelfahrt, das

15 O Kommentar descreve detalhadamente os dados concretos do encontro, que eu apenas recordo aqui: em 25 de maio de 1960, Celan e Nelly Sachs encontram-se pela primeira vez, após quase dois anos de correspondência; no dia 26 (Ascensão de Cristo), acontece o conhecido diálogo em Zurique, no hotel Zum Storchen; no dia seguinte, Nelly Sachs viaja para Meeresburg, para a entrega do prêmio Droste e Celan retorna para Paris. Sobre o cenário do encontro, o Kommentar afirma: “Die Vorderfront des Zürcher Hotels 'Zum Storchen' liegt am Ufer der Limmat. Auf dem Vorplatz und im ersten Stock gibt es eine Terrasse, von der aus man auf das Großmünster auf der anderen Seite der Limmat blickt.”. (67).

16 De acordo com Joachim Schulze: "In dem Gedicht Zürich, zum Storchen datiert Celan die Begegnung mit Nelly Sachs auf den Himmelfahrtstag, jedoch ist bereits Lesern, die nicht an einen möglichen Zusammenhang mit dem Sternenlied gedacht haben, aufgefallen, daß es sich dabei wohl nicht nur um eine bloße Datierung nach dem christlichen Kalender handelt." (Schulze 1993: 218). Uma leitura poetológica também é sugerida por Michael Krämer, embora o desenvolvimento de seu artigo seja questionável. (KRÄMER 1994: 50-51) 


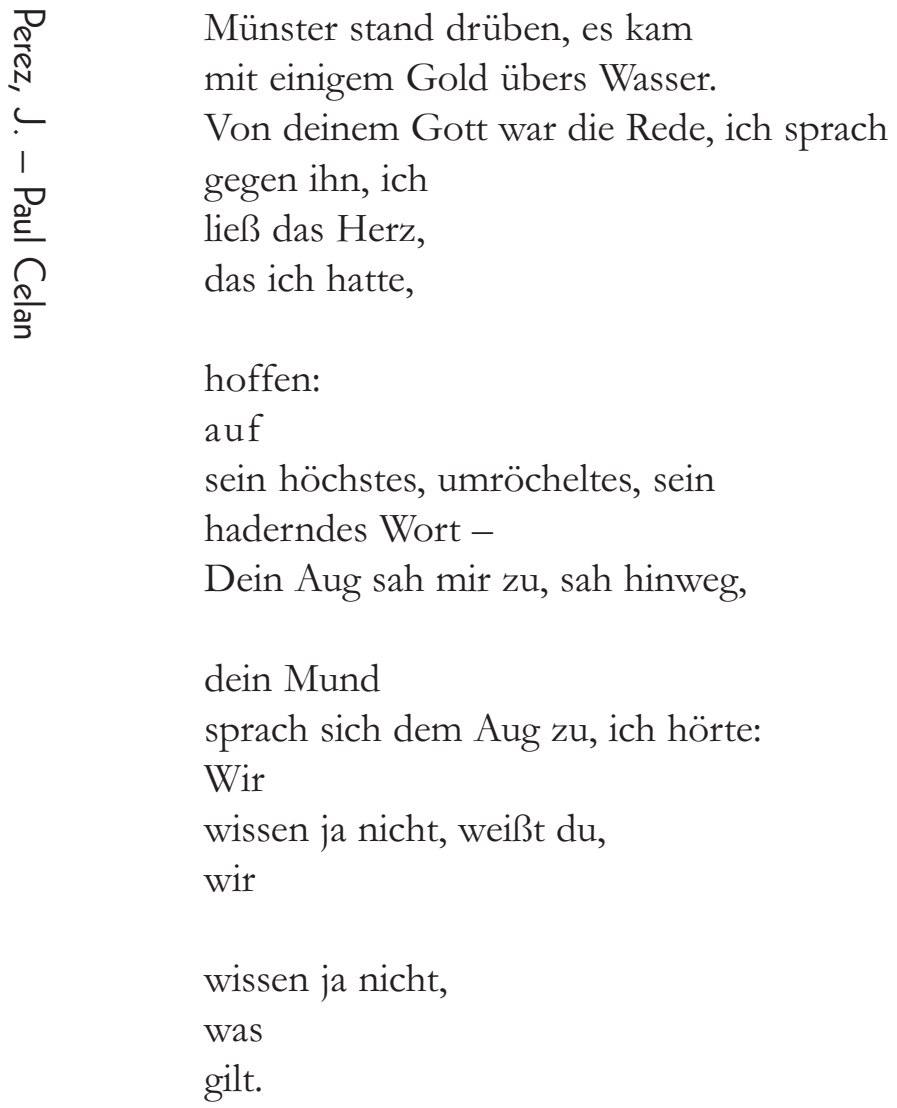

O poema representa muito mais do que a oposição de Celan a "Deus", pois o diálogo acontece "am Tag einer Himmelfahrt" - em um dia, em que o próprio eu inicia uma ascensão ${ }^{17}$ - ou um caminho por um céu abissal, como sugere a figura de Lenz, que determina o pensamento poetológico de Celan na época. O céu como abismo aparece sempre que Celan se refere ao extermínio dos judeus e à possibilidade de extermínio de qualquer ser humano.

Pode-se observar ao menos em dois momentos que Celan tem em mente a figura de Lenz ao escrever Zürich, zum Storchen: no próprio poema, na medida em que a imagem do mosteiro refletida na água aparece inverti-

17 Que "Himmelfahrt" não se refere mais à festa católica, mostra o primeiro rascunho do poema. Celan escreve "Am Himmelfahrtstag", risca-o e escreve ao lado: "am Tag einer Himmelfahrt." (BCA. 6.2: 59) 
da para os protagonistas do diálogo, e em uma anotação para a BüchnerRede de 30 de maio, mesmo dia da criação do poema:

... letzte Worte Büchners auf dem Sterbebett, Lenzens Worte (Moskau) sind nicht überliefert - es ist die Rückkehr in das eben noch Stimmhafte, wie im Wozzeck - es ist die Sprache als Involution, Sinnentfaltung in der einen, wortfremden Silbe: - es ist die im durchröchelten Stammeln erkennbare 'Stammsilbe', Sprache als in den Keim Zurückgekehrte - der Bedeutungsträger ist der sterbliche Mund, dessen Lippen sich nicht mehr ründen. Muta cum liquida, vokalisch gestützt, der Reimlaut als Selbstlaut.(TCA 1999: 182, N. 738)

Assim, no nono verso, que representa uma mudança no poema, abre-se um caminho sobre o abismo. O "discurso/conversa" ("Rede") da primeira estrofe continua com a clara oposição do eu ao "teu Deus" (“deinen Gott”); mas o objetivo verdadeiro da discussão é ouvir a voz de alguém que parece arquejar. A palavra mortal, considerada aqui a palavra "altíssima" ("das höchste Wort”) ${ }^{18}$-, quase não é mais uma palavra, mas uma “im durchröchelten Stammeln erkennbare 'Stammsilbe" - uma sílaba dita com dificuldade, quase um sopro. O momento a ser perseguido no poema não é aquele em que se diz algo, mas aquele em que a linguagem - ou o discurso ("Rede") - cede lugar ao sofrimento da criatura. ${ }^{19}$

Celan continua a desenvolver o pensamento do sopro, do respiro (“Atem”), no mesmo dia:

18 A busca pela palavra também se mostra concretamente no primeiro rascunho: sobre „Wort", Celan escreve primeiro " sein / letztes", ao lado, "haderndes Wort", sobre "letztes", ele escreve "höchstes, sein"; então reflete mais uma vez e escreve: "letztes/ sein aller- / höchstes", mas risca todas essas possibilidades. No rascunho seguinte, ele ainda hesita entre "sein letztes" e "sein höchstes Wort", repetindo o pronome: "auf [sein] höchstes, [sein] umröcheltes, sein haderndes Wort”. (BCA 6.2: 59-60).

19 Paul Celan também repete a formulação da carta a Hermann Kasack no dia 30 de maio: "30.5.60/ im Gebirg /... wir sind bei Büchner, bei Lenz - wir sind beim Gedicht. - /Gedichte: Unendlichsprechung von Sterblichkeit und Umsonst". (TCA 1999: 182, N. 737). 
'Was auf der Lunge, das auf der Zunge', pflegte meine Mutter zu sagen. Das hat mit dem Atem zu tun. Man sollte es endlich lernen, im Gedicht diesen Atem, diese Atemeinheit mitzulesen; in den Kolen ist der Sinn oft wahrer gefügt und gefugt als im Reim; Gestalt des Gedichts: das ist Gegenwart des Einzelnen, Atmenden. - (TCA 1999: 108, N. 262)

Como parte da reflexão poetológica desenvolvida por Paul Celan na primeira metade de 1960, o diálogo do poema Zürich, zum Storchen torna-se ainda mais dramático. A “ascensão” traz a esperança de uma palavra: "sein höchstes, umröcheltes, sein haderndes Wort". A atitude de Jó, que muitas vezes é atribuída ao eu-lírico (e portanto a Celan), refere-se a Deus: a palavra desejada ( $\operatorname{cin}$ Wort) é a "höchste" ("altíssima”), quando arqueja ("umröchelt"), quando assim se assemelha à palavra de um mortal e quando, como um mortal, "luta" ("hadert").

Sabe-se há muito que os últimos versos são uma citação quase literal do diálogo real entre Celan e $\mathrm{Sachs}^{20}$ e que a amizade entre os dois oscilava entre admiração e controvérsia (BOLLACK 1994) entre outros motivos, porque Celan questionava a si mesmo e a todos os sobreviventes do nazismo. No mesmo dia em que escreve o poema, Celan trata desta questão mais uma vez, colocando-se contra Rilke:

\subsubsection{Büchner-Rede -}

"Überstehen ist alles" - nein, es ist nicht alles: nein, überleben ist unanständig, man muß, als Überlebender, erst recht um sein Leben schreiben. - und es ist kein Zufall, daß diese Worte ein Zitat sind ein Zitat, übernommen und mit weit weniger als dem eigenen Lebensatem verantwortet; ja, von der Artistik ist es nur ein Schritt zur posthumen Beschönigung. (TCA 1999: 156, N. 579)

A decisão ética exigida por Celan ultrapassa a recusa do nazismo e de todo tipo de totalitarismo: trata-se de uma abertura ao conhecimento e à afirma-

20 "Sachs allein. 'Ich bin ja gläubig'. Als ich darauf sage, ich hoffte, bis zuletzt lästern zu können: 'Man weiß ja nicht, was gilt'.” (Celan/Nelly SACHS: 41). 
ção de cada indivíduo, perceptível e presente por seu "sopro vital" ("Lebensatem").

Em carta de 20 de março de 1960 a Werner Weber, Celan já estabelecia o nexo entre 'ethos', abertura, percepção (do mal e da presença humana) e linguagem:

Ihre Gedanken zum 'Augenblick' des Gedichts: das berührt mich, inmitten all des in der letzten Zeit Erfahrenen und Wahrgenommenen (und im Hinblick auf das wohl noch Wahrzunehmende), besonders. Sprache, zumal im Gedicht, ist Ethos - Ethos als schicksalhafter Wahrheitsentwurf. (Und wenn es nur diese - gewiss nicht einer kleinräumigen 'Subjektivität' zuzuschreibende - Erfahrung gäbe: dass man der Wahrheit des Gedichts nachleben muss, - wenn es nur diese Erfahrung gäbe (und es gibt sie!), sie könnte genügen. Aber wieviele sind es denn heute, die solche Aspekte des Dichterischen überhaupt wahrnehmen? Die das Gedicht wahrnehmen als menschliche - und mithin einmalige und vom Geheimnis der Einmaligkeit begleitete - Präsenz? Wieviele sind es wohl, die mit dem Wort zu schweigen wissen, bei ihm bleiben, wenn es im Intervall steht, in seinen 'Höfen', in seiner - schlüsselfernen - Offenheit, das Stimmhafte aus dem Stimmlosen fällend, in der Systole die Diastole verdeutlichend, welt- und unendlichkeitssüchtig zugleich - Sprache, wie Valéry einmal sagt, in statu nascendi, freiwerdende Sprache, Sprache der Seelenmonade Mensch - und, wenn ich auch noch das hinzufügen darf, Sprache in statu moriendi, Sprache dessen, der Welt zu gewinnen sucht, weil er - ich glaube, das ist ein uralter Traum der Poesie - weltfrei zu werden hofft, frei von Kontingenz. (Fremde Nähe 1997: 398)

Para Paul Celan, a abertura está ligada à presença humana e é uma dimensão da própria palavra que pretende se dirigir a tal presença: na carta, o autor transforma um aspecto temporal da palavra - o intervalo (das "Intervall") - em um aspecto espacial - os pátios ("Höfen"), e chega a uma imagem abstrata e paradoxal - "schlüsselferne Offenheit". Paul Celan não busca abolir o paradoxo da presença humana, mas abre-se a ele e percebe que ao "Geheimnis der Einmaligkeit" pertencem tanto o "Stimmlose" quanto o "Stimmhafte", a "Systole" e "Diastole", o mundo e o infinito, o "status 
nascendi" e o "status moriendi". Assim, a abertura torna-se uma dimensão ética do poema.

Fiel a esta concepção da poesia, o poema Zürich, zum Storchen, muito mais do que apresentar uma polêmica, configura o momento em que a linguagem se abre à percepção da presença humana: é o mesmo momento em que o céu se inverte em abismo, nos versos 9 a 12, e em que a efemeridade do humano é percebida. A terceira estrofe ainda representa a tentativa de retornar ao discurso, à "Rede"; no entanto, na quarta estrofe, o olhar abrese a uma presença humana concreta através do silêncio: Ao ver o tu falar (“dein Mund / sprach sich dem Aug zu”), como Lucile em Der Meridian, o eu escuta não apenas a pessoa que abandona sua posição, mas um tu que hesita e reflete nas pausas de sua respiração. ("Wir / wissen ja nicht, weißt du, / wir / wissen ja nicht, / was gilt.”)

Em sua agenda, Celan anota: "Man weiß ja nicht, was gilt"; no poema, ele altera o pronome: nesse sentido, as pausas das últimas estrofes representam o momento do encontro entre os sujeitos do poema, não porque eles concordem, mas porque, nas pausas, se mostra um tu que hesita, arqueja e sofre e, dessa maneira, encontra a hesitação e o sofrimento do outro.

A negação de "Gott" e "Rede" em "Zürich, zum Storchen" torna-se um caminho para a afirmação do outro, porque o eu enfim ouve o respiro de uma criatura: palavra por palavra, nas pausas, abre-se o difícil reconhecimento de um não-saber. O movimento do texto vai de um discurso geral ao falar hesitante de um indivíduo. De "Zuviel" e "Zuwenig" de um discurso "Rede" (que se refere à relação com Deus e a "isso" - "da-zu" - ou seja, ao extermínio dos judeus), através da "ascensão" ("Himmelfahrt") de um eu - que na verdade desce a um abismo -, espera-se uma palavra que só será alcançada no último verso: uma palavra que respira com dificuldade. Paradoxalmente, os versos que hesitam em relação "ao que conta" afirmam com absoluta certeza uma presença humana - hesitam em relação a tudo, mas não duvidam do homem.

Assim, ao longo dos ciclos de Die Niemandsrose, revela-se uma poesia que se coloca contra qualquer abstração ideológica para servir a uma radical afirmação da presença humana. 
Zurique, zum Storchen

Para Nelly Sachs

Do tanto se falava, do

tão pouco. Do Ti

e do anTi-, do

enturvecer com o claro, do

De Tu-

do isso.

No dia da ascensão, a

catedral ali em frente, vinha

com algum ouro por sobre a água.

Do teu Deus se falava, eu falava

contra ele, eu

deixei o coração, o que eu tinha,

esperando:

por

sua palavra altíssima, que arqueja

que contende -

Teu olho me via, desvia,

tua boca

consolava-se no olho, eu ouvia:

\section{Nós}

não sabemos, sabe,

nós

não sabemos,

o que é

que conta.

(Tradução de Mauricio Mendonça Cardozo - UFPR) 


\section{D্ত Referências bibliográficas}

- Celan, Paul. Gesammelte Werke in fünf Bänden. Hrsg. Beda Allemann u.

I Stefan Reichert. Frankfurt a. M., Suhrkamp 1983, Bd. 3. (GW)

Celan, Paul. Die Niemandsrose. Historisch-kritische Ausgabe. Bd. 6.1. Gedichte; 6.2. Apparat. Besorgt v. der Bonner Arbeitstelle für die CelanAusgabe. Hrsg. Axel Gellhaus unter Mitarbeit v. Holger Gehle u. Andreas Lohr in Verbindung mit Rolf Bücher. Frankfurt a.M., Suhrkamp 2001. (BCA 6.1/6.2)

Celan, Paul. Sprachgitter. Historisch-kritische Ausgabe. Bd. 5.1. Gedichte; 5.2. Apparat. Besorgt v. der Bonner Arbeitstelle für die Celan-Ausgabe. Hrsg. Holger Gehle unter Mitarbeit v. Andreas Lohr. Frankfurt a.M., Suhrkamp 2002. (BCA 6.1/6.2)

Celan, Paul. Der Meridian. Endfassung. Vorstufen. Materialien. Hrsg. Bernard Böschenstein, bearbeitet v. Heino Schmull. Frankfurt a. M., Suhrkamp 1999. (TCA)

\section{Correspondência}

Carta de Paul Celan a Johannes Bobrowski, Paris, 24. November 1959. In: Johannes Bobrowski oder Landschaft mit Leuten. Bearb. von Reinhard Tgahrt in Zs.arb. mit Ute Doster, Marbach a. N. 1993, 425. (BoBrowski)

Wiedemann, Barbara. (Hg.) Paul Celan - Nelly Sachs: Briefwechsel. Frankfurt a. M., Suhrkamp 1993. (Celan/SACHS)

Seng, Joachim (Hg.). „Theodor W. Adorno und Paul Celan. Briefwechsel 1960-1968“. In: Frankfurter Adorno Blätter VIII, 2003. 177-202. (CELAAN/ ADORNo)

\section{Crítica}

André, Robert. Gespräche vom Text zu Text. Celan - Heidegger - Hölderlin. Hamburg, Meiner 2001.

Bollack, Jean. "Paul Celan und Nelly Sachs. Geschichte eines Kampfs". Neue Rundschau. 105 (1994), 119-134. 
. Sinn wider Sinn. Wie liest man? Gespräche mit Patrick Llored. Göttingen, Wallstein 2003.

. „Ein Bekenntnis zur Ungebundenheit“. Celans Gedicht Psalm. In: SpeIER, Hans-Michael. Hg. Gedichte von Paul Celan. Stuttgart: Reclam 2002, 83-93.

Fremde Nähe. Celan als Übersetzer. Eine Ausstellung des Deutschen Literaturarchivs. Hg. v. Axel Gellhaus. Marbach a. N., Deutsche Schillergesellschaft 1997. (Fremde Nähe)

FrIEDRICH, Hugo. Die Struktur der modernen Lyrik. Von Baudelaire bis zur Gegenwart. Hamburg, Rowohlt 1956.

Gellhaus, Axel. „Poetologie des Übersetzens: ,Fremde Nähe‘. Übersetzen - die andere Seite der Dichtung." In: Fremde Nähe. Celan als Übersetzer. Eine Ausstellung des Deutschen Literaturarchivs. Hg. v. Axel Gellhaus. Marbach a. N., Deutsche Schillergesellschaft 1997.

. Enthusiasmus und Kalkül. Reflexionen über den Ursprung der Dichtung. München, Fink 1995.

. "Das Gespräch im Gebirg - Paul Celans impliziter Dialog mit Adorno über die Möglichkeit von Dichtung nach Auschwitz". Zeitschrift für deutsche Philologie, hrsg. von Werner Besch u.a. 123. Band 2004, Sonderheft: Literatur und Geschichte. Neue Perspektiven. Hrsg. von Michael Hofmann und Hartmut Steinecke, Berlin 2004, 209-219.

Harbusch, Ute. Gegenübersetzung. Paul Celans Übertragungen der französischen Symbolisten. Diss. RWTH-Aachen, 2001. Göttingen, Wallstein 2005.

Kohler-LuginbüHL, Dorothea. Poetik im Lichte der Utopie: Paul Celans poetologische Texte. Bern; Frankfurt a. M; New York, Lang 1986.

Lehmann, Jürgen. (Hg.) Kommentar zu Paul Celans Die Niemandsrose. Hg.. Heidelberg, Winter 1997. (Kommentar)

KRÄMER, Michael. "Wir wissen ja nicht, was gilt". Zum poetologischen Verfahren bei Nelly Sachs und Paul Celan. Versuch einer Annäherung." In: Kessler, M., Wertheimer, J. Hg. Nelly Sachs. Neue Interpretationen. Tübingen, Stauffenburg 1994. 35-67. 
D Mandeistam, Ossip. „Das Wort und die Kultur“. Über den Gesprächpartner. N Gesammelte Essays 1913-1924. Frankfurt a. M., Fischer 1994.

I Schestow, Leo. "Die Nacht zu Gethsemane (Pascals Philosophie)." Ariadne. $\stackrel{\square}{\rightleftharpoons} \quad$ Jahrbuch der Nietzsche Gesellschaft. München 1925.

$\frac{\curvearrowright}{\frac{\curvearrowright}{\sigma}}$ SChUlZE, Joachim. "Rauchspur und Sefira. Über die Grundlagen von Paul Celans Kabbala-Rezeption”. In: Celan-Jahrbuch 5 (1993), 193-246.

SenG, Joachim. Auf den Kreiswege der Dichtung. Zyklische Kompositionen bei Paul Celan am Beispiel der Gedichtbände bis Sprachgitter. Heidelberg, Winter 1998.

"Die wahre Flaschenpost". Zur Beziehung zwischen Theodor W. Adorno und Paul Celan". In: Frankfurter Adorno Blätter VIII, 2003, 151176.

Wiedemann, Barbara. (Hg.) Paul Celan - Die Goll-Affäre. Dokumente zu einer 'Infamie'. Frankfurt a. M., Suhrkamp 2000. 